\title{
ASSESSMENT OF APPLE AND CARROT POMACES FOR COST-EFFECTIVE REACTIVE BLACK 5 BIOREMOVAL BY PENICILLIUM CITRINUM
}

\author{
EKIN DEMIRAY* \\ Department of Biology, Faculty of Science, Ankara University, Dögol Street Tandogan, 06100 Ankara, Turkey.
}

\begin{abstract}
In this study, Reactive Black 5 bioremoval by Penicillium citrinum was investigated. Common agricultural by-products of the food industry, such as apple and carrot pomaces were used as carbon sources. Carrot and apple pomace were pretreated hydrothermally, and the effects of some critical parameters such as pH, initial biomass and dye loadings on Reactive Black 5 bioremoval were investigated. $P$. citrinum removed $80.87 \%$ of the dye in the presence of $16 \%$ carrot pomace, pH 5 and $225.9 \mathrm{mg} / \mathrm{L}$ initial dye loading, respectively. The maximum specific dye uptake rate was found as $52.92 \mathrm{mg} / \mathrm{g}$ under the same conditions. Moreover, notably bioremoval was observed even in high Reactive Black 5 concentrations such as $758.2 \mathrm{mg} / \mathrm{L}$. The results showed that $P$. citrinum is a suitable microorganism for dye removal, and carrot and apple pomaces can be evaluated for microbial growth as a cheap carbon sources.
\end{abstract}

Keywords: Apple pomace, bioremoval, carrot pomace, Penicillium citrinum, Reactive Black 5.

\section{INTRODUCTION}

Synthetic dyes are frequently used in different industrial areas such as textile, tannery, paper, metal or plastics. During the dyeing process, a considerable amount of synthetic dyes can be released to the water sources, and this situation causes severe environmental and health concerns [1]. In the textile industry, Reactive Black 5 (RB5) is one of the most commonly used anionic dyes, and it has specific functional groups which make fast and stable bindings with the textile product. Therefore, the removal of RB5 contaminated wastewaters is particularly problematic for the environment $[2,3]$.

In this context, chemical, physical or physicochemical methods such as adsorption, ozonation or precipitation are frequently used for decolourisation of synthetic azo dyes [4]. However, these methods have some disadvantages, such as high cost or operational problems. On the other hand, biological treatment is a cheap and eco-friendly alternative to physical or chemical methods. Since the different microorganisms such as bacteria, yeasts or fungi can remove these effluents from wastewaters, bioremoval has become one of the most commonly used decolourisation methods. Among the microorganisms, fungi are attractive agents because they can transform or degrade complex dyes with various mechanisms. Therefore, extensive studies are carried out in the literature about fungal dye bioremoval $[5,6]$.

Agricultural wastes possess a vital role for biotechnological applications such as fibre or biofuel production [7,8]. Furthermore, in the literature, agricultural wastes are evaluated as adsorbent [9] or growth media for dye bioremoval [10] frequently.

Agricultural wastes are abundant and cheap raw materials and have three vital elements: Cellulose, hemicellulose and lignin. However, to obtain the monomeric sugars, which will be used by microorganisms, some pretreatment methods are required [11]. During the pretreatment, some inhibitory compounds which are hazardous for the organisms can be released to the growth environment [12]. Therefore, selecting the raw materials which contain free sugar or susceptible to pretreatment agent is advantageous for cost-effective microbial development.

Apple and carrot are essential products of the agricultural industry and every year, million tons of apple and carrot are processed from the juice industry. Therefore, tremendous amounts of apple and carrot pomaces are generated in the World annually. These by-products are abundant, cheap and ready-available and also have rich sugar content [13,14]. For this reason, extensive researches are performed about the biotechnological applications of apple and carrot pomaces $[15,16]$.

Penicillium citrinum is a mesophilic and widespread endophytic fungus which exists different plants such as soybean, wheat or citrus species [17]. P. citrinum is a biotechnologically important microorganism because of its heavy metal biosorption capacity [18], metabolite or enzyme production $[19,20]$.
Additionally, in the literature, $P$. citrinum was also used as a bioremoval agent [21]. However, there is no attention in the literature about the usage of agricultural wastes such as apple and carrot pomaces as a growth medium for reactive black 5 bioremoval of $P$. citrinum. Therefore, in this study, apple and carrot pomaces were used as a microbial growth environment for the Penicillium citrinum and the RB5 bioremoval capacity of the $P$. citrinum was investigated for the first time. For a more economical and eco-friendly bioremoval process, pomaces were pretreated with hydrothermally. Critical parameters such as $\mathrm{pH}$, initial pomace and RB5 loadings were also examined. The current study is the first report which shows apple and carrot pomaces pretreated with hydrothermally can be evaluated for the bioremoval of the RB5 by $P$. citrinum as a microbial growth media.

\section{EXPERIMENTAL}

\section{Preparation of carrot and apple pomaces}

Carrot pomace (CP) was obtained from BELSO Co./Ankara-Turkey. Apple pomace (AP) was provided by Göknur Gida Co./Niğde/Turkey. Pomaces were dried in the oven at $70{ }^{\circ} \mathrm{C}$ for overnight and were kept in the screw-capped bottles until experiments. For stock pomace solution, $300 \mathrm{~g} / \mathrm{L}$ each pomace were autoclaved in $121{ }^{\circ} \mathrm{C}$ for $15 \mathrm{~min}$ and were filtered through Whatman No:1 paper. The liquid fraction of apple and carrot pomaces were used in bioremoval experiments.

\section{Isolation of microorganism}

Fungi were isolated from soil samples Ankara/Turkey. Samples were centrifuged and spreaded Petri plates, which contained $1.5 \%$ agar, $8 \%$ pomace and $200 \mathrm{mgL}^{-1} \mathrm{RB} 5$ with penicillin. Samples were incubated $30 \pm 1{ }^{\circ} \mathrm{C}$. Fungal cells that can grow in the presence of RB5 were selected and purified by streaking the cells repeatedly on the carrot and apple pomaces media plates. The pure cultures were kept at $4{ }^{\circ} \mathrm{C}$.

\section{PCR and sequencing}

The exponentially growing culture of the isolates was used for genomic DNA isolation and amplification of internal transcribed spacer (ITS) regions of $18 \mathrm{~S}$ rDNA by conventional PCR. Genomic DNA of yeast strains was isolated using DNABiz kit. ITS regions were then PCR amplified using ITS1 (5' TCCGTAGGTGAACCTGCGG 3') and ITS4 (5' TCCTCCGCTTATTGATA TGC 3') primers. PCR was carried out with using MyTaq DNA polymerase (Bioline UK), and the thermal cycling conditions were set as; 1 min initial denaturation step at $94{ }^{\circ} \mathrm{C}$, followed by 30 cycles of $45 \mathrm{~s}$ at $94{ }^{\circ} \mathrm{C}$ for denaturation, $45 \mathrm{~s}$ at $55^{\circ} \mathrm{C}$ for annealing and $45 \mathrm{~s}$ at $72{ }^{\circ} \mathrm{C}$ for elongation. The sequencing of the DNA was performed at the ABI 3100 Genetic Analyzer device in an external laboratory (Refgen, Ankara, Turkey). Strains were identified according to the assessment of the results of DNA, 18S rDNA gene sequence and PCR analyses performed.

*Corresponding author email: edemiray@ankara.edu.tr 


\section{Culture conditions}

All experiments were carried out in $30{ }^{\circ} \mathrm{C}$, and agitation speed was adjusted to $100 \mathrm{rpm}$, inoculation rate was set as $5 \%$, and $250 \mathrm{~mL}$ Erlenmeyer flasks working volume with $100 \mathrm{~mL}$ were used in the experiments. Uninoculated Erlenmeyer flasks containing RB5 were used as control samples to observe any reactions of the media with the dye. Each of these experiments and measurements described below to follow the daily changes in the samples throughout the incubation period were performed in triplicate.

\section{Bioremoval assays}

To select the type of agricultural waste, $8 \%$ apple and carrot pomace media, which contained $200 \mathrm{mg} / \mathrm{L} \mathrm{RB5}$ were prepared. $\mathrm{pH}$ was adjusted to 5 . The fungal cells were acclimated in the $200 \mathrm{mg} / \mathrm{L}$ RB5 contained apple and carrot pomace media by transferring twice before measuring dye concentrations.

The effects of initial $\mathrm{pH}$ on dye bioremoval were investigated at $\mathrm{pH} 5,7$ and 9 in the presence of $8 \%$ carrot pomace medium contained $200 \mathrm{mgL}^{-1} \mathrm{RB}$. The fungal cells were grown in the preincubation medium for acclimation and were transferred to the fresh medium twice before experiments.

Five different carrot pomace media $(8 \%, 16 \%, 32 \%, 64 \%$ and $100 \%)$ were prepared to investigate the effect of initial biomass loading. To determine the effect of initial RB5 concentration, four different dye concentrations (approximately 200, 400, 600 and $800 \mathrm{mgL}^{-1}$ ) were prepared in the presence of $16 \%$ carrot pomace at $\mathrm{pH} 5$. In all experiments, AP and CP media without $P$. citrinum were also used in order to check the bioremoval of AP and CP media alone.

\section{Analytical methods}

During the incubation period, a $3 \mathrm{~mL}$ sample was taken daily from each flask. Samples were centrifuged at $6000 \mathrm{rpm}$., for $10 \mathrm{~min}$ (Hettich Rotofix 32A). The concentration of Reactive Black 5 was determined by measuring the absorbance at $600 \mathrm{~nm}$ (Shimadzu UV 2001 spectrophotometer). Cell-free carrot and apple pomace media were used as the blank. For the measurement of microbial growth at the end of the incubation period, the biomass concentration was determined by measuring dry weight. Reducing sugar concentration was determined according to the DNS method [22].

The RB5 bioremoval of fungus was investigated in a batch system as a function of the type of raw material, initial $\mathrm{pH}$, dye and biomass concentrations. The percentage uptake of dye or heavy metal was calculated from Eq. (1):

\section{Bioremoval (\%): $\left(C_{0} C_{f}\right) / C_{0} \mathrm{X} 100$}

In this equation, $C_{0}$ represents the initial concentration of RB5 as $\mathrm{mgL}^{-1}$ and $C_{f}$ represents the final concentration of RB5 after the bioremoval.

The maximum specific dye uptake rates were calculated according to Eq. (2) which has shown below.

$$
q_{m}:\left(C_{0} C_{f}\right) / X_{m}
$$

In this equation, $C_{0}$ represents the initial concentration of RB5 as $\mathrm{mg} / \mathrm{L}$ and $C_{f}$ represents the final concentration of RB5 after the bioremoval and $q_{m}$ shows the maximum amount of dye or heavy metal per unit dry weight of fungus (mg/L) and $\mathrm{X}_{m}$ is the maximum dried cell mass $(\mathrm{g} / \mathrm{L})$.

\section{RESULTS AND DISCUSSION}

Identification of the fungus and the effect of type of raw materials on RB5 bioremoval

The fungus strain was isolated from soil samples that were collected from a textile factory area located near Ankara/Turkey. Molecular phylogenetic analysis conducted based on nuclear internal transcribed spacer (nrITS) rDNA region of the isolate revealed $100 \%$ sequence similarity with Penicillium citrinum.

Therefore the isolate was considered as Penicillium citrinum. ITS rDNA sequence of the isolate was deposited into NCBI GenBank under the accession number of MT325923.
Reducing sugar concentrations of the hydrothermally pretreated AP and CP were determined before bioremoval assays. $36.26 \mathrm{~g} / \mathrm{L}$ and $63.56 \mathrm{~g} / \mathrm{L}$ reducing sugar were found in AP and CP, respectively. These stock media were diluted to $8 \%$ and were used for bioremoval experiments.

RB5 bioremoval capacities of the $8 \% \mathrm{AP}$ and $\mathrm{CP}$ media were compared in this part of the study. Initial RB5 concentrations were $203.8 \mathrm{mg} / \mathrm{L}$ for AP and 213.6 $\mathrm{mg} / \mathrm{L}$ for $\mathrm{CP}$, respectively. The data in Figure 1 depict that $P$. citrinum removed higher concentrations of RB5 in the presence of CP. In the CP medium, the highest bioremoval rate was detected as $77.13 \%$ at the end of the $5^{\text {th }}$ day. On the other hand, the highest bioremoval observed in AP was calculated as $17.43 \%$ at the end of the $5^{\text {th }}$ day of incubation.

Dry weight and maximum specific dye uptake rates of $P$. citrinum in the presence of AP and CP media were also calculated. The data in Table 1 depicts that the type of raw material affects the dye uptake rates. The maximum specific dye uptake rate of the $P$. citrinum was observed as $13.15 \mathrm{mg} / \mathrm{g}$ in the AP medium. In the same conditions, this value increased to $37.42 \mathrm{mg} / \mathrm{g}$ when $\mathrm{CP}$ was used as the growth medium.

Moreover, both AP and CP media, bioremoval rates decreased after the $5^{\text {th }}$ day of incubation, respectively, and RB5 bioremoval rates of the $P$. citrinum were found as $11.17 \%$ and $64.33 \%$ in the presence of AP and CP respectively at the end of the seven days incubation period. Because the higher bioremoval rates were obtained from $\mathrm{CP}$, further studies were carried out with carrot pomace.

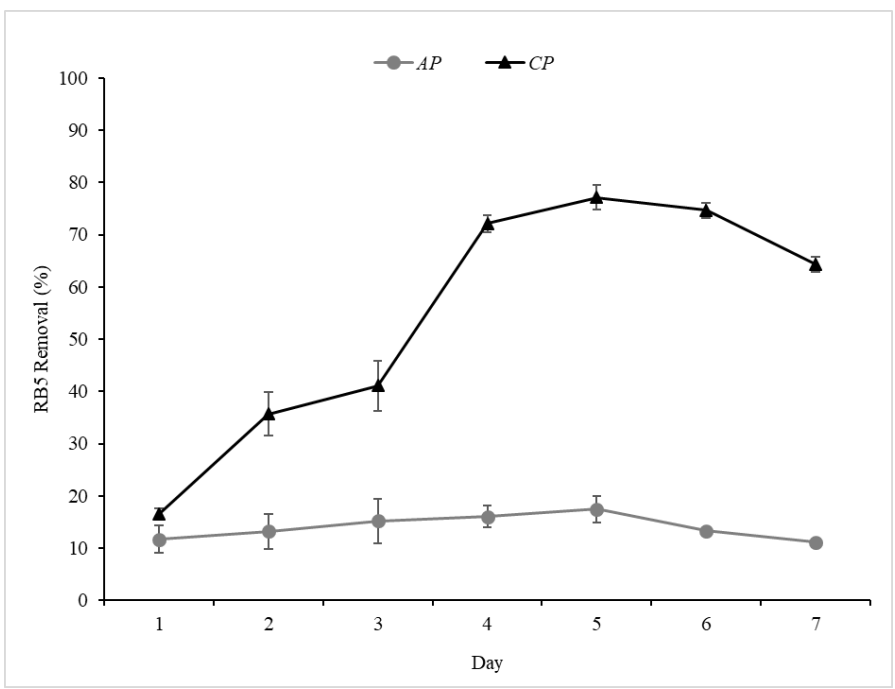

Figure 1. RB5 bioremoval of $P$. citrinum in the presence of apple and carrot pomaces $\left(\mathrm{C}_{\mathrm{ORB}}\right.$ : Nearly $200 \mathrm{mg} / \mathrm{L}, \mathrm{pH}: 5,8 \%$ initial carrot and apple pomaces loading).

The data in Figure and Table 1 depict that both AP and CP media supported the growth of $P$. citrinum, and $P$. citrinum is able to remove RB5 both in the AP and $\mathrm{CP}$ media. However, it can be concluded that $\mathrm{CP}$ is more favourable growth environment for $P$. citrinum. In the current study, nearly two times higher reducing sugar was observed in CP than the AP. Carrot is one of the few plants which consist of the free sugars in the vacuoles. Furthermore, sucrose, fructose and glucose are the major sugars of the carrot [23]. AP and CP were only pretreated hydrothermally $\left(121{ }^{\circ} \mathrm{C}\right.$ for $\left.15 \mathrm{~min}\right)$ in the current study in order to ensure a more economical bioremoval process. Thus, it can be concluded that the susceptible structure of the CP resulted in higher sugar concentration and, eventually, more efficient bioremoval. Because of the higher bioremoval rate was obtained from the $\mathrm{CP}$ medium, further studies were carried out with carrot pomace medium.

Other studies in the literature showed that $P$. citrinum is a potential bioremoval agent, and our findings are consistent with Muthezhilan et al. [24] who reported the methylene blue removal capacity of the P. citrinum was $72.6 \%$. In another study, Iandolo et al. [25] found that the decolourization rate of acid wastewater contained dye as $50 \%$ by Pleurotus ostreatus when apple residues were used as the growth medium. 
In the current study, $P$. citrinum removed $77.13 \%$ of RB5 at the end of the $5^{\text {th }}$ day in CP medium and $213.6 \mathrm{mg} / \mathrm{L}$ initial dye loading. Similarly, BergstenTorralba et al. [26] showed that Penicillium simplicissimum INCQS 40211 removed almost $100 \%$ of the reactive red 198 , reactive blue 214 , and reactive blue 21 dyes when initial dye concentrations adjusted as $200 \mathrm{mg} / \mathrm{L}$.

\section{Effect of pH on RB5 bioremoval}

In the current study, the effect of $\mathrm{pH}$ value on RB5 bioremoval was examined using the samples which have about $200 \mathrm{mgL}^{-1}$ initial dye concentrations. The experiments were performed in the $\mathrm{pH}$ ranging from 5 to 9 , and initial $\mathrm{CP}$ loading was adjusted as $8 \%$. According to the results in Figure 2, the maximum bioremoval rate was detected as $77.13 \%$ from $\mathrm{pH} 5$, and bioremoval rates decreased parallel with increased $\mathrm{pH}$ values. $P$. citrinum removed $65.07 \%$ and $47.01 \%$ of the $\mathrm{RB} 5$ in the presence of $\mathrm{pH} 7$ and 9, respectively. In all $\mathrm{pH}$ values, bioremoval rates were decreased after the $5^{\text {th }}$ days of incubation. In the current study, the highest bioremoval was found in the presence of $\mathrm{pH} \mathrm{5}$; therefore, further experiments were performed in $\mathrm{pH} 5$.

Moreover, it was observed that increased $\mathrm{pH}$ values resulted in decreased dye uptake rates, and the highest $\mathrm{q}_{m}$ value was detected in $\mathrm{pH} 5$ as $37.42 \mathrm{mg} / \mathrm{g}$. In the presence of $\mathrm{pH} 7$ and $9,34.07$ and $27.69 \mathrm{mg} / \mathrm{g}$ specific dye uptake values were detected, respectively.

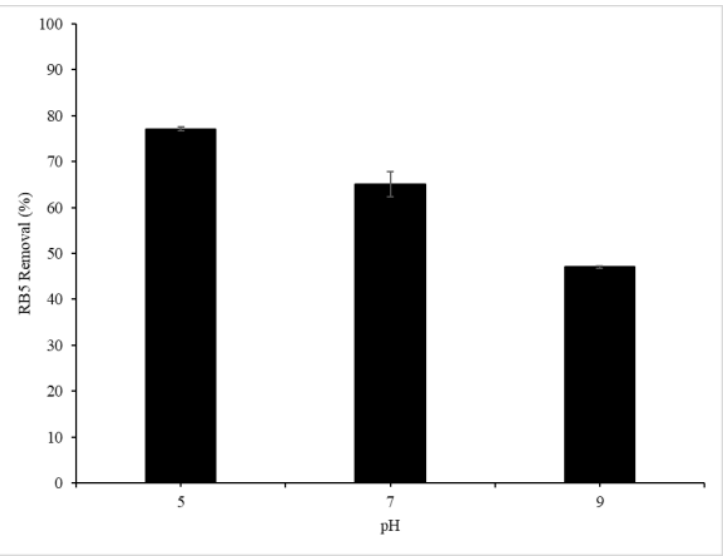

Figure 2. RB5 bioremoval of $P$. citrinum in the presence of carrot pomace medium prepared with different $\mathrm{pH}$ values $\left(\mathrm{C}_{\mathrm{ORB}}\right.$ : Nearly $200 \mathrm{mg} / \mathrm{L}$, initial carrot loading: $8 \%$, incubation time: 5 days).

$\mathrm{pH}$ is a crucial factor for bioremoval studies. Since $\mathrm{pH}$ can affect the dye and cell structure, bioremoval can change dramatically depending on $\mathrm{pH}$ values [27]. Bioremoval yields belong to the $P$. citrinum in the presence of different $\mathrm{pH}$ values were given in Figure 2 and Table 1. According to the data, slightly acidic $\mathrm{pH}$ values are more favourable for $P$. citrinum, and the highest bioremoval was observed in $\mathrm{pH}$ 5. It was previously shown that slight acidic $\mathrm{pH}$ values between 4 and 6 are favourable for some fungi species. In a study, for instance, the optimum $\mathrm{pH}$ range for Reactive Brilliant Red bioremoval was determined between 4 and 5 for Penicillium sp. QQ [28]. In another study focused on bioremoval of remazol blue by Aspergillus versicolor, researchers found similar bioremoval rates $(70.27 \%$ ) at $\mathrm{pH} 5$ when the initial dye concentration was 230.2 $\mathrm{mg} / \mathrm{L}[29]$.

Furthermore, the maximum specific dye uptake rate was observed in $\mathrm{pH} 5$, and increased $\mathrm{pH}$ values resulted in decreased bioremoval and specific dye uptake rates. In a previous report, Reactive Black 5 removal capacity of the dried Penicillium restrictum decreased from $13.35 \mathrm{mg} / \mathrm{g}$ to $8 \mathrm{mg} / \mathrm{g}$ when $\mathrm{pH}$ was increased from 4 to 8 . This finding was proposed to be related to the anionic character of the RB5 [30].

\section{Effect of initial biomass loading on RB5 bioremoval}

Five different initial carrot pomace loadings were tested to examine their effect on RB5 bioremoval. The data in Figure 3 depict that $16 \%$ initial CP loading resulted in the highest bioremoval rates and the concentrations that exceed $16 \%$ initial CP loading caused significantly lower removal. The highest bioremoval was observed in $16 \% \mathrm{CP}$ loading as $80.87 \%$. Furthermore, in $8 \%, 32 \%, 64 \%$ and
100\% initial CP loadings, $77.13 \%, 36.44 \%, 35.32 \%$ and $18.71 \%$ RB5 removal were obtained, respectively.

It was also observed that $16 \%$ of $\mathrm{CP}$ loading resulted in faster bioremoval period. In the presence of $16 \% \mathrm{CP}$, the highest bioremoval was found at the end of the four days of the incubation period. However, in other groups, the maximum bioremoval was observed at the end of the five days of incubation.

Similarly to $\mathrm{pH}$, increased initial biomass loading caused decreased specific dye uptake rates. In the presence of $16 \%, \mathrm{CP}$ loading $\mathrm{q}_{m}$ value was obtained as $52.92 \mathrm{mg} / \mathrm{g}$. On the other hand, $25.09 \mathrm{mg} / \mathrm{g}, 22.76 \mathrm{mg} / \mathrm{g}$ and $14.34 \mathrm{mg} / \mathrm{g}$ dye uptake rates were found in the presence of $32 \%, 64 \%$ and $100 \%$ initial CP loadings, respectively (Table 1).

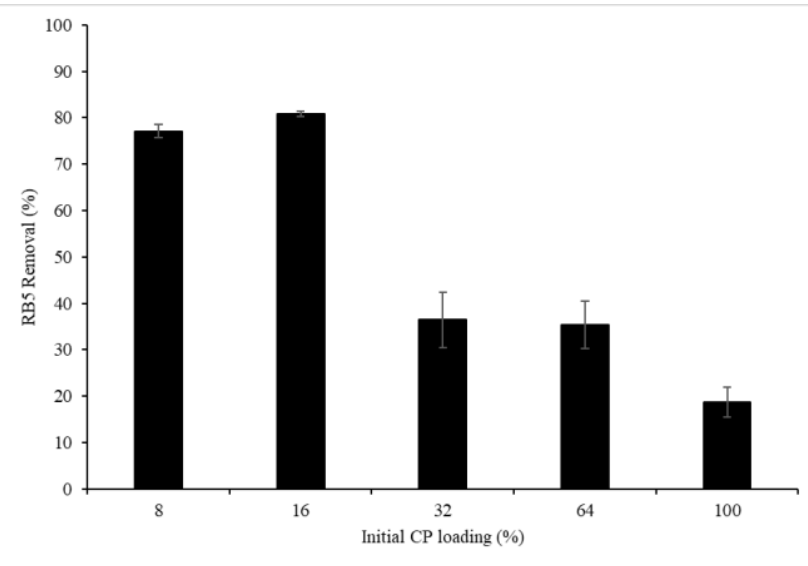

Figure 3. RB5 bioremoval of $P$. citrinum in the presence of different initial carrot pomace laodings $\left(\mathrm{C}_{\mathrm{oRB}}\right.$ : Nearly $200 \mathrm{mg} / \mathrm{L}, \mathrm{pH}: 5$, incubation time: 4 days for $16 \%, 5$ days for $8 \%, 32 \%, 64 \%$ and $100 \%)$.

Initial biomass loading is an essential criterion for microbial growth. In this context, different CP loadings ranging from $8 \%$ to $100 \%$ were tested to determine their effects on RB5 bioremoval of $P$. citrinum. Results were given in Figure 3 and Table 1. According to the data, $16 \%$ initial $\mathrm{CP}$ loading gave the highest removal rates among the tested CP loadings, and increased CP loadings caused significantly lower bioremoval and specific dye uptake amounts. In the current study, carrot pomaces were hydrothermally $\left(121{ }^{\circ} \mathrm{C}\right.$ for $15 \mathrm{~min}$ in autoclave) pretreated, and neither acidic or basic agents were used. Nevertheless, during autoclave pretreatment, some inhibitory compounds such as levulinic acid, 5hydroxymethylfurfural, syringaldehyde or formic acid can be released to the growth medium [31]. Therefore, it can be concluded that decreasing bioremoval may be related to the inhibitory compounds which are released to the growth environment during pretreatment. For instance, in a study, Karpe et al. [32] found a significant difference between hexose and pentose utilization of $P$. citrinum from autoclaved and non-autoclaved groups of grape wastes.

In this study, the highest bioremoval rates and specific dye uptake rates were obtained from $16 \%$ initial CP loading. Thus, $16 \%$ of CP was used for further experiments.

Table 1. Maximum specific dye uptake rates $\left(\mathrm{q}_{m}\right)$ of $P$. citrinum in the presence of apple and carrot pomace media (Initial biomass loading: $8 \%, \mathrm{pH} 5$ ).

\begin{tabular}{|l|c|c|c|c|c|}
\hline Biomass type & $\begin{array}{c}\text { Biomass loading } \\
(\mathbf{\%})\end{array}$ & $\mathbf{p H}$ & $\begin{array}{c}\text { Initial RB5 loading } \\
(\mathbf{m g} / \mathbf{L})\end{array}$ & $\begin{array}{c}\mathbf{X}_{\boldsymbol{m}} \\
(\mathbf{g} / \mathbf{L})\end{array}$ & $\begin{array}{c}\mathbf{q}_{\boldsymbol{m}} \\
(\mathbf{m g} / \mathbf{g})\end{array}$ \\
\hline Apple pomace & 8 & 5 & 203.8 & 2.7 & 13.15 \\
\hline \multirow{5}{*}{ Carrot pomace } & \multirow{3}{*}{8} & 5 & 213.6 & 4.2 & 37.42 \\
\cline { 2 - 6 } & & 7 & 214.7 & 4.1 & 34.07 \\
\cline { 2 - 6 } & & 9 & 217.6 & 3.7 & 27.64 \\
\cline { 2 - 6 } & 16 & 5 & 225.9 & 3.4 & 52.92 \\
\cline { 2 - 6 } & 32 & 5 & 220.4 & 3,2 & 25.09 \\
\cline { 2 - 6 } & 64 & 5 & 219.1 & 3.4 & 22.76 \\
\hline
\end{tabular}




\section{Effect of initial RB5 loading on bioremoval}

In order to test the effect of initial RB5 loading on bioremoval, four different RB5 concentrations were prepared. Experiments were carried out in $16 \%$ initial $\mathrm{CP}$ loading and $\mathrm{pH}$ 5. The data in Figure 4 indicated that increased RB5 concentrations caused lower bioremoval performance. $P$. citrinum removed $80.87 \%$ of the dye in the presence of $225.9 \mathrm{mg} / \mathrm{L}$ initial RB5 loading. On the other hand, the bioremoval rate declined to $55.91 \%$ when the initial biomass loading increased to $758.2 \mathrm{mg} / \mathrm{L}$.

Contrary to $\mathrm{pH}$ and initial biomass loading, specific dye uptake rates increased parallel with increased dye loading. The highest specific dye uptake rate was found as $157.00 \mathrm{mg} / \mathrm{g}$ when the $758.2 \mathrm{mg} / \mathrm{L} \mathrm{RB} 5$ was used as initial dye concentration. These values were only $100.69 \mathrm{mg} / \mathrm{g}$ and $152.34 \mathrm{mg} / \mathrm{g}$ when the initial RB5 loadings were 407.3 and $649.6 \mathrm{mg} / \mathrm{g}$, respectively (Table 2).

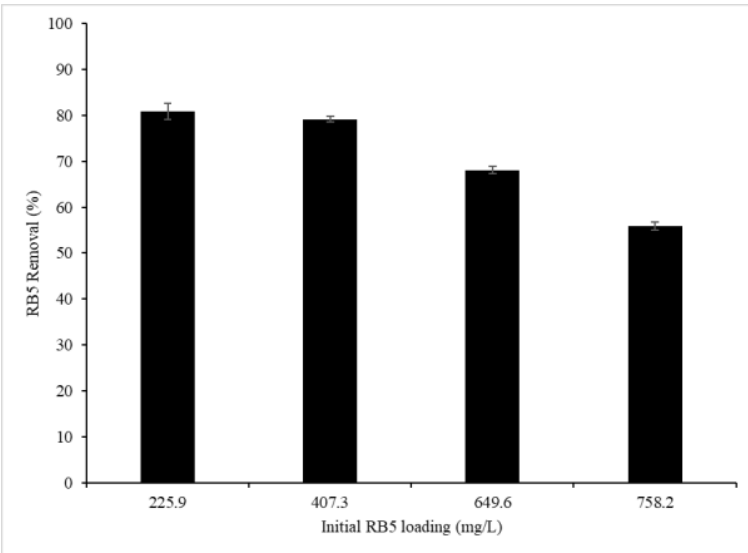

Figure 4. RB5 bioremoval of $P$. citrinum in the presence of different initial RB5 loadings (Initial carrot pomace loading: 16\%, pH: 5, incubation time: 4 days).

Table 2. Maximum specific dye uptake rates $\left(\mathrm{q}_{m}\right)$ of $P$. citrinum in the presence of different carrot pomace media (Initial carrot pomace loading: 16\%, pH: 5).

\begin{tabular}{|c|c|c|c|}
\hline \multirow{2}{*}{ Biomass type } & $\begin{array}{c}\text { Initial RB5 loading } \\
(\mathbf{m g} / \mathbf{L})\end{array}$ & $\begin{array}{c}\mathbf{X}_{\boldsymbol{m}} \\
(\mathbf{g} / \mathbf{L})\end{array}$ & $\begin{array}{c}\mathbf{q}_{\boldsymbol{m}} \\
(\mathbf{m g} / \mathbf{g})\end{array}$ \\
\hline \multirow{3}{*}{ Carrot pomace } & 407.3 & 3.2 & 100.69 \\
\cline { 2 - 4 } & 649.6 & 2.9 & 152.34 \\
\cline { 2 - 4 } & 758.2 & 2.7 & 157.00 \\
\hline
\end{tabular}

$P$. citrinum cells were also tested for their ability to remove RB5 in the presence of different initial dye concentrations $(225.9-758.2 \mathrm{mg} / \mathrm{L})$ in $\mathrm{CP}$ medium. The results were shown in Figure 4 and Table 2. The highest bioremoval was observed in $225.9 \mathrm{mg} / \mathrm{L}$ initial dye concentration, and notably decolourization was detected even $758.2 \mathrm{mg} / \mathrm{L}$ initial RB5 loadings. Similar to dye removal, microbial growth of the $P$. citrinum was not dramatically affected by increased dye concentrations. The data in Table 2 showed that $P$. citrinum could grow in high RB5 amounts. These results showed that the RB5 concentrations used in the study were not toxic to $P$. citrinum. On the other hand, maximum specific dye uptake rates increased parallel with the increased dye concentration. This situation can be explained with the dye uptake capacity of the $P$. citrinum.

Decreased bioremoval rate in the presence of increased dye concentrations was shown in previous studies. In a study, in the presence of molasses sucrose, Penicillium chrysogenum MTCC 6477 removed $90.11 \%$ and $87.0 \%$ of the RB5 when the initial dye loadings were $275 \mathrm{mg} / \mathrm{L}$ and $500 \mathrm{mg} / \mathrm{L}$, respectively [33]. In another study, $P$. citrinum removed $72 \%$ of the basic violet when the initial dye concentration was used as $20 \mathrm{mg} / \mathrm{L}$. This value was only found as $28 \%$ when the initial dye concentration increased to $100 \mathrm{mg} / \mathrm{L}$ [21]. In another study, Trametes versicolor removed $83.3 \%$ of remazol black $\mathrm{B}$ in the presence of $195.8 \mathrm{mg} / \mathrm{L}$ initial dye. When the dye concentration increased to $385.6 \mathrm{mg} / \mathrm{L}$, the removal rate decreased to $77.0 \%$. On the other hand, the dye uptake capacity of the $T$. Versicolor increased from $25.9 \mathrm{mg} / \mathrm{g}$ to $45.6 \mathrm{mg} / \mathrm{g}$ under the same conditions [34].

\section{CONCLUSIONS}

In this study, the effects of type of agricultural wastes, $\mathrm{pH}$, initial biomass and dye loading on bioremoval of anionic dye RB5 by Penicillium citrinum were investigated. P. citrinum removed the $77.13 \%$ of the RB5 in the presence of carrot pomace, whereas this value was $17.43 \%$ when the apple pomace was used as a carbon source. On the other hand, $16 \%$ initial CP loading resulted in the highest bioremoval yields. Moreover, a considerable amount of bioremoval was obtained even in high initial RB5 concentrations, such as $758.2 \mathrm{mg} / \mathrm{L}$. The highest removal of the $P$. citrinum was observed as $80.87 \%$ in the presence of $\mathrm{pH} 5, \% 16$ initial CP and $225.9 \mathrm{mg} / \mathrm{L}$ initial dye loadings.

Lignocellulosic wastes such as carrot or apple pomaces are important byproducts of the food industry. Because of their low cost and high carbohydrate contents, they can be used as alternative carbon sources in the bioremoval of hazardous compounds. In the current study, P. citrinum cells tolerated high concentrations of Reactive Black 5 in the media containing apple and carrot pomace sugars as carbon sources. In summary, the results indicated that $P$. citrinum has a high potential for removing Reactive Black 5 and carrot pomace is a suitable carbon source for fungal growth

\section{ACKNOWLEDGEMENTS}

The author is grateful to Dr Gönül Dönmez and Dr Sevgi Ertuğrul Karatay for their valuable contributions to the preparation of the manuscript, isolation and identification of the Penicillium citrinum. This work was not supported by any research grant.

\section{REFERENCES}

1. D.A. Yaseen, M. Scholz. Textile dye, Int. J. Environ. Sci. Technol. 16, 1226, (2019).

2. K. Murugesan, A. Dhamija, I. H. Nam, Y. M. Kim, Y.S. Chang, Dye Pigment. 75, 184, (2007).

3. D. Jager, D. Kupka, M. Vaclavikova, L. Ivanicova, G. Gallios, Chemosphere. 190, 416, (2018)

4. L. Ayed, S. Achour, A. Bakhrouf, Water SA. 37, 26, (2011)

5. Y. Fu, T. Viraraghavan, Bioresour Technol.79, 262, (2001).

6. S. K. Sen, S. Raut, P. Bandyopadhyay P, S. Raut, Fungal Biol Rev. 30, 133 (2016).

7. A. Clementz, P. A. Torresi, J. S. Molli, D. Cardell, E. Mammarella, J. C. Yori, LWT. 100, 374, (2019).

8. F. Figuerola, M. L. Hurtado, A. M. Estévez, I. Chiffelle, F. Asenjo, Food Chem. 91, 395, (2005).

9. V. S. Munagapati, V. Yarramuthi, Y. Kim, K. M. Lee, D. S.Kim, Ecotoxicol Environ Saf. 148, 601, (2018).

10. S. E. Karatay, G. Dönmez, Ecol Eng. 73, 224, (2014).

11. S. Paul, A. Dutta, Resour Conserv Recycl. 130, 164, (2018).

12. E. Palmqvist, B. Hahn-Hägerdal, Bioresour Technol. 74, 25, (2000).

13. F. Vendruscolo, P. M. Albuquerque, F. Streit, E. Esposito, J. L. Ninow, Crit Rev Biotechnol. 28, 1, (2008).

14. S. Surbhi, V. Rc, R. Deepak, J. Hk, Y. Kk, Int J Chem Stud. 6, 2921, (2018)

15. S. Pathania, N. Sharma, S. Handa, Biocatal Biotransformation. 35, 450, (2017).

16. R. S. Singh, K. Chauhan, J. Singh, A. Pandey, C. Larroche, Food Technol Biotechnol. 56, 31, (2018).

17. S. A. Khan, M. Hamayun, H. Yoon, H. Y. Kim, S. J. Suh, S. K. Hwang, BMC Microbiol. 8, 1, (2008).

18. C. Pang, Y. H. Liu, X. H. Cao, M. Li, G. L. Huang, R. Hua, Chem Eng J. 170, 1, (2011)

19. Y. Tashiro, H. Ueno, M. Takaba, S. Hayashi, Curr Microbiol. 74, 1114, (2017).

20. Y. Gu, P. Ding, Z. Liang, Y. Song, Y. Liu, G. Chen, Fitoterapia. 127, 207, (2018).

21. M. R. Deivasigamni, P. Ramalingam, J Adv Chem. 13, 6438, (2017).

22. G. L. Miller, Anal Chem. 31, 426, (1959).

23. N. R. Aimaretti, C. V. Ybalo, M. L. Rojas, F. J. Plou, J. C. Yori, Bioresour Technol. 123, 727, (2012).

24. R. Mutzehilan, S. Yogananth, S. Jayalakshmi, Res J Microbiol. 3, 204 (2008)

25. D. Iandolo, A. Amore, L. Birolo, G. Leo, G. Olivieri, V. Faraco, Bioresour Technol. 102, 7603, (2011).

26. L.R. Bergsten-Torralba, M. M. Nishikawa, D. F. Baptista, D. P. Magalhães M. da Silva, Brazilian J Microbiol. 40, 808, (2009).

27. B. E: Wang, Y. Y. Hu, L. Xie, K. Peng, Bioresour Technol. 99, 794, (2008).

28. M. Gou, Y. Qu, J. Zhou, F. Ma, L. Tan, J Hazard Mater. 170, 314, (2009). 
29. B. E. Taştan, S. Ertuğrul, G. Dönmez, Bioresour Technol. 101, 870, (2010).

30. C. F. Iscen, I. Kiran, S. Ilhan, J Hazard Mater. 143, 335, (2007).

31. H. B. Klinke, L. Olsson, A. B. Thomsen, B. K. Ahring, Biotechnol Bioeng. 81, 737, (2003).

32. A. V. Karpe, I. H. Harding, E. A. Palombo, Ind Crops Prod. 59, 228, (2014).
33. M. A. Kumar, S. Keerthana, A. Pani, D. Suresh, C. B. Lakshmikantha, M. Seenuvasan, Int J Biomed Eng Technol. 2, 1, (2011).

34. Z. Aksu, N. K. Kiliç, S. Ertuğrul, G. Dönmez, Enzyme Microb Technol. 40, 1167, (2007). 